\title{
PENGARUH CITRA DESTINASI DAN PERSEPSI HARGA TERHADAP LOYALITAS PENGUNJUNG DI OWABONG MELALUI KEPUASAN SEBAGAI VARIABEL MEDIASI
}

\author{
Oryz Agnu Dian Wulandari'), Agus Suroso, Refius Pradipta Setyanto2) \\ Program Pascasarjana Magister Manajemen Universitas Jendral Soedirman Purwokerto ${ }^{1)}$ \\ Fakultas Ekonomi dan Bisnis Magister Manajemen Universitas Jendral Soedirman Purwokerto ${ }^{2)}$ \\ Email corresponding author : oryzagnu10@gmail.com
}

\begin{abstract}
This research is motivated by the increasing economic growth of the nation which is currently influenced by the world of tourism in Indonesia. This research was conducted at Owabong (Bojongsari Water Tourism Object) with the aim of examining the influence of destination image, perspectives on innovation and price perceptions of loyalty and intention to return through satisfaction as a mediating variable. Data were collected by questionnaire method on 145 visitors at Bojongsari Water Tourism Object obtained by using purposive sampling technique. The method used is descriptive quantitative.

The results of this study are destination image, perception of innovation and perceived price and satisfaction as mediating variables together have a positive and significant influence on loyalty and intention to return. While the loyalty variable has a positive but not significant effect on the intention to visit again.
\end{abstract}

Keywords: Destination image, perceived price, satisfaction, loyalty.

\begin{abstract}
ABSTRAK
Penelitian ini dilatar belakangi dengan meningkatnya pertumbuhan ekonomi bangsa yang saat ini dipengaruhi oleh dunia pariwisata di Indonesia. Penelitian ini dilakukan di Owabong ( Obyek Wisata Air Bojongsari ) dengan tujuan yakni menguji pengaruh citra destinasi, perspsi inovasi dan persepsi harga terhadap loyalitas dan niat berkunjung kembali melalui kepuasan sebagai variabel mediasi. Data dikumpulkan dengan metode kuisioner terhadap 145 pengunjung di Obyek Wisata Air Bojongsari yang diperoleh dengan menggunakan teknik purposive sampling. Metode yang digunakan adalah deskriptif kuantitatif.

Hasil dari penelitian ini adalah citra destinasi, persepsi inovasi dan persepsi harga serta kepuasan sebagai variabel mediasi secara bersama-sama memiliki pengaruh positif dan signifikan terhadap loyalitas dan niat berkunjung kembali. Sedangkan variabel loyalitas memiliki pengaruh positif tetapi tidak signifikan terhadap niat berkunjung kembali.
\end{abstract}

Kata kunci : Citra destinasi, persepsi harga, kepuasan, loyalitas.

\section{PENDAHULUAN}

Meningkatnya pertumbuhan ekonomi bangsa saat ini dipengaruhi oleh dunia pariwisata di Indonesia. Dunia pariwisata juga diharapkan dapat memajukan pendapatan daerah untuk mengembangkan potensi daerah menjadi lebih baik. Salah satu obyek wisata yang potensial di Kabupaten Purbalingga adalah Obyek Wisata Air Bojongsari (OWABONG). Dengan meningkatnya persaingan antar industri pariwisata menyebabkan owabong mengalami fluktuasi jumlah pengunjung. Berikut tabel fluktuasi jumlah pengnjung dari tahun $2012-2016$. 
Tabel 1. Fluktuasi Jumlah Pengunjung Tahun 2012 - 2016

\begin{tabular}{rc}
\hline Tahun & Jumlah Pengunjung \\
\hline $\mathbf{2 0 1 2}$ & 929.781 \\
$\mathbf{2 0 1 3}$ & 895.626 \\
$\mathbf{2 0 1 4}$ & 787.475 \\
$\mathbf{2 0 1 5}$ & 793.263 \\
$\mathbf{2 0 1 6}$ & 969.468 \\
\hline
\end{tabular}

Dari data pada tabel tersebut Owabong mengalami masalah fluktuasi jumlah pengunjung selama tahun 2012 - 2016. Dimana pada tahun 2012 - 2014, jumlah pengunjung di Owabong mengalami penurunan, sedangkan 2015 - 2016 mengalami peningkatan jumlah pengunjung. Citra destinasi merupakan aspek yang harus dimiliki oleh industri pariwisata seperti Owabong karena citra destinasi merupakan tahap terpenting dalam proses menentukan tujuan wisata. Selain dari aspek citra destinasi, masih ada aspek lain yang tidak kalah penting yaitu inovasi yang dilakukan oleh obyek wisata. Harga merupakan salah satu faktor penting bagi perusahaan karena dapat meningkatkan pendapatan, tetapi strategi harga bukanlah salah satu cara yang tepat untuk mengatasi persoalan di dalam perusahaan . Penelitian terdahulu yang dilakukan oleh (Wang et al., 2009; Chi dan Qu, 2008; Prayag dan Ryan, 2012; Bigne et al.,2001) mengenai hubungan citra destinasi terhadap kepuasan pengunjung. Hasil yang diperoleh yaitu adanya pengaruh positif antara citra destinasi terhadap kepuasan pengunjung, hal tersebut berkaitan dengan pengalaman suatu perjalanan yang terdiri dari berbagai aspek antara lain lingkungan alam, sosial, akomodasi dan lain sebagainya yang mampu membuat kepuasan bagi pengunjung. Hasil tersebut berbeda dengan yang dilakukan oleh Chen \& Tsai (2007) dan Bosque dan Martin (2008) yang memperoleh hasil bahwa citra destinasi tidak memiliki pengaruh yang positif terhadap kepuasan pengunjung, hasil tersebut dikarenakan citra destinasi yang baik yang dimiliki suatu obyek wisata belum mampu meningkatkan kepuasan yang tinggi bagi pengunjung.

Penelitian yang dilakukan oleh (Cronin et al., 2000; Anderson et al., 1994; Herman et al, 2007) menunjukan hasil bahwa persepsi harga memiliki pengaruh terhadap kepuasan, hal tersebut terjadi karena ketika konsumen tidak mempermasalahkan harga yang ditawarkan dengan memiliki persepsi positif terhadap harga maka kepuasan akan meningkat. Sedangkan penelitian yang dilakukan oleh Inayatul (2017) menunjukan bahwa persepsi harga tidak memiliki pengaruh terhadap kepuasan pengujung. Hal tersebut dikarenakan seorang konsumen tidak terlalu memperhatikan harga ketika melakukan kunjungan, konsumen akan tetap melakukan kunjungan walaupun harga yang ditawarkan sedikit mahal.

Penelitian yang dilakukan oleh (Kozak, 2003; Bigne et al., 2001; Chen dan Tsai, 2007; Prayag dan Ryan, 2012) menujukan bahwa kepuasan memiliki pengaruh positif terhadap loyalitas dan niat berkunjung kembali, hal tersebut dikarenakan loyalitas dan niat berkunjung kembali adalah sebuah konsekuensi dari model kepuasan wisata. Kepuasan telah dianggap sebagai yang paling terkenal dalam evaluasi untuk membangun loyalitas dan niat untuk berkunjung kembali. Sedangkan penelitian oleh Gigih (2017) memperoleh hasil bahwa kepuasan konsumen tidak memiliki pengaruh terhadap loyalitas pelanggan, hal tersebut menunjukan bahwa tingginya tingkat kepuasan belum tentu akan meningkatkan loyalitas pada suatu obyek wisata. Selain itu adanya perbedaan penelitian terdahulu maka perlu dilakukan penelitian lebih lanjut mengenai variabel yang akan diteliti. Tujuan dari penelitian ini adalah untuk mengetahui dan menganalisis pengaruh citra destinasi, persepsi harga terhadap loyalitas melalui kepuasan sebagai variabel mediasi. 
Berdasarkan latar belakang yang telah diuraikan di atas, maka penulis bermaksud mengadakan penelitian"Pengaruh Citra Destinasi, dan Persepsi Harga terhadap Loyalitas Melalui Kepuasan sebagai Variabel Mediasi di Owabong". Dengan mengetahui besarnya pengaruh tersebut, maka perusahaan akan lebih mudah dalam menentukan strategi yang tepat dan sesuai dengan kondisi serta keadaan yang sedang dihadapi Owabong.

\section{TINJAUAN PUSTAKA}

\section{Loyalitas}

Menurut Dick dan Basu (1994), loyalitas memiliki hubungan erat antara sikap relatif dengan pembelian ulang, hubungan erat tersebut dipandang sebagai mediasi oleh norma sosial dan faktor situasional yaitu kognitif, afektif, dan anteseden konatif dari sikap relatif yang diidentifikasi memiliki pengaruh terhadap loyalitas.Griffin (2005), mengungkapkan karakteristik pelanggan yang loyal sebagai berikut : a. Pelanggan melakukan pembelian secara berulang, yang artinya pelanggan melakukan pembelian produk atau jasa sebanyak dua kali atau lebih; b. Melakukan pembelian antar lini produk, artinya pelanggan membeli semua barang atau jasa yang ditawarkan dan yang sesuai dengan kebutuhan; c. Merekomendasikan produk atau jasa kepada orang lain artinya mengajak orang lain agar membeli barang atau jasa pada suatu perusahaan; d. Pelanggan tidak terpengaaruh dengan produk atau jasa yang sejenis yang ditawarkan oleh pesaing.

Tahap loyalitas menurut Griffin (2005) terbagi atas 7 tingkat, yaitu : 1). Suspect : Yang termasuk pada bagian ini adalah semua pembeli produk atau jasa dalam pemasaran, yang artinya menyadari akan suatu produk atau jasa perusahaan atau tidak memiliki kecenderungan terhadap pembelian; 2). Prospect : pelanggan yang potensial memiliki daya tarik terhadap perusahaan tetapi pelanggan tersebut belum mengambil suatu keputusan untuk menjalin kerjasama dengan perusahaan; 3). Disqualified Prospect : prospect yang memungkinkan seseorang mengetahui keberadaan barang atau jasa tertentu, tetapi tidak mampu untuk membeli suatu barang atau jasa; 4). First Time Customers : konsumen yang baru pertama melakukan pembelian dan mereka masih menjadi konsumen baru; 5). Repeat Customers : Pembelian ulang dilakukan oleh pelanggan untuk menunjukkan loyalitas suatu perusahaan tetapi pelanggan tersebut lebih mempuyai dorongan untuk membeli secara pasif daripada aktif terhadap perusahaan; 6). Clients : hubungan erat antara konsumen dengan supplier yang saling memperlihatkan keuntungan; 7). Advocates : layaknya Client, advocates memberikan dorongan atau motivasi positif kepada perusahaan dengan cara merekomendasikan kepada orang lain.

\section{Kepuasan}

Kepuasan wisatawan adalah suatu perbandingan antara harapan dan pengalaman yang memberikan suatu evaluasi setelah melakukan kunjungan J.C.Castro et.al (2017 ). Menurut Irawan (2004), terdapat beberapa faktor yang akan mendorong kepuasan pelanggan, faktor tersebut yakni:Kualitas Produk; Harga; Service Quality; Emotional Factor; Biaya dan Kemudahan.

\section{Mengukur Kepuasan Pelanggan}

Kotler (2005), mengidentifikasi beberapa metode dalam mengukur kepuasan pelanggan sebagai berikut : a. Survei berkala, Metode ini dilakukan untuk mengukur kepuasan yang dilakukan konsumen secara langsung dengan cara memberikan suatu pertanyaan kepada konsumen dengan tujuan mengukur niat pembelian kembali dan memungkinkan adanya konsumen untuk merekomendasikan suatu produk atau merek kepada orang lain; b. Tingkat kehilangan konsumen (Lost customer analysis),metode tingkat kehilangan konsumen ini dilakukan karena suatu perusahaan mengalami kegagalan dalam memberikan kepuasan terhadap konsumen. Masalah ini dapat diselesaikan dengan menghubungi konsumen yang 
tidak lagi melakukan pembelian atau yang sudah beralih ke produk atau perusahaan lain untuk mengatahui alasannya;c. Pembelanja misterius (Ghost Shopping), maksud dari pembelanja misterius adalah suatu perusahaan mempekerjakan beberapa pekerja atau pembelanja misterius (Ghost shopper) untuk dijadikan sebagai konsumen yang melakukan pembelian atas suatu produk ke perusahaan pesaing dan kemudian melaporkan apa yang menjadi masalah perusahaan, sehingga perusahaan dapat melakukan evaluasi menjadi lebih baik; d. Wawancara dilakukan secara langsung dengan melakukan survei, dimana akan akan memperoleh hasil mengenai tanggapan dan umpan balik langsung dari konsumen.

\section{Citra Destinasi}

Andreassen, et.al (1997), citra destinasi dipercaya dapat menciptakan kepuasan terhadap konsumen, dimana Citra destinasi digunakan pengujung sebagai bahan evaluasi dalam membandingkan obyek wisata yang lain. Dimensi citra destinasi menurut Qu, et.al (2011) sebagai berikut :Cognitive destination image : artinya respon atau persepsi suatu keyakinan terhadap destinasi. Tujuannya agar suatu pengetahuan mudah diingat. Cognitive image terdiri dari Quality of experience, touristic attractions, environment and infrastruktur, Entertainment/outdoor activities dan cultural traditions, Unique destination image : Suatu tanggapan atau persepsi wisatawan mengenai keunikan suatu destinasi yang berbeda dengan yang tempat wisata lain. Unique image terdiri dari natural environment, appealing destination, dan local attraction, Affective destination image : Pernyataan mengenai penilaian suka atau tidak suka terhadap suatu destinasi. Affective image terdiri dari pleasant, arousing, relaxing, dan exciting.

\section{Persepsi Harga}

Harga menurut Manahati (2016), adalah nilai dari suatu produk yang ditawarkan. Sedangkan persepsi harga menurut Burton et,.al (1998), berkaitan erat dengan persepsi pelanggan terhadap kualitas, nilai dan keyakinan.

Kotler (2005) berpendapat, ada enam langkah dalam menentukan kebijakan penetapan harga, sebagai berikut : 1). Memilih tujuan penetapan harga, Suatu perusahaan memutuskan dimana ingin memposisikan tawaran psaranya. Makin jelas tujuan suatu perushaan, makin mudah menetapkan harga; 2). Menentukan permintaan, Harga yang ditetapkan perusahaan akan membuat adanya permintaan yang berbeda dari konsumen dan akan memiliki pengaruh berbeda terhadap tujuan pemasaran perusahaan;

3). Memperkirakan Biaya, permintaan konsumen terhadap perusahaan dalam memperkirakan biaya dapat digunakan perusahaan untuk menentukan harga tertinggi yang dilakukan atas produknya; 4). Menganalisis Biaya, harga dan tawaran pesaing, Sautu perusahaan harus mempertimbangkan harga pesaing terdekat untuk memiliki keputusan apakah dapat mengenakan harga yang lebih tinggi, sama, atau lebih murah daripada pesaing; 5). Memilih metode penetapan harga, perusahaan memilih metode penetapan harga yang tepat untuk dapat menetapkan batas harga tertinggi. Dalam memilih metode penetapan harga, kotler membahas tujuh metode penetapan harga, antara lain : Harga Markup ( Markup Pricing ), Penetapan harga sasaran pengembalian ( Target-return-pricing ),Penetapan harga persepsi nilai ( Perceived - Value - Pricing), Penetapan harga nilai ( Value Pricing ), Penetapan harga umum ( Going - Rate - Pricing ), Penetapan harga tipe lelang ( Action- type pricing ), Penetapkan harga kelompok ( Group Pricing ).; 6). Memilih harga akhir,dalam memilih harga akhir, perusahaan harus mempertimbnagkan faktor tambahan seperti faktor harga psikologis, penetapan harga berbagi laba dan resiko, pengaruh unsur bauran pemasaran, kebijakan penetapan harga dan dampak harga terhadap pihak lain. 


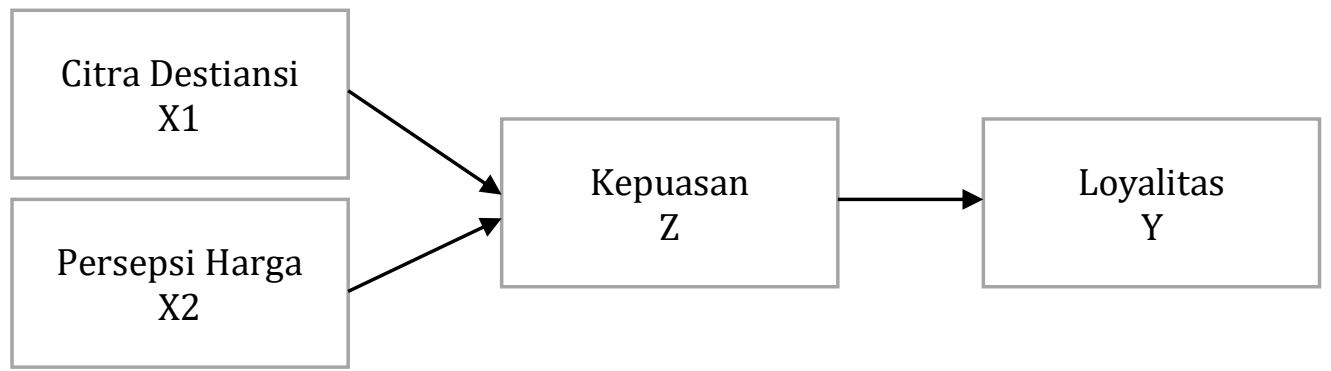

Gambar 1 Model Penelitian

Hipotesis

Hipotesis dalam penelitian ini berdasarkan rumusan masalah, tinjauan pustaka dan penelitian terdahulu adalah :

H1 : Citra Destinasi memiliki pengaruh positif terhadap kepuasan pengunjung di Owabong.

H2 : Persepsi harga memiliki pengaruh positif terhadap kepuasan pengunjung di Owabong.

H3 : Kepuasan pengunjung memiliki pengaruh positif terhadap loyalitas pengunjung di Owabong.

\section{METODE PENELITIAN}

Metode Analisis Data yang digunakan dalam penelitian ini adalahmetode deskriptif kuantitatif yaitu mencari atau mengumpulkan data yang diperlukan dan bersumber dari perusahaan dandiuraikan sehingga memberikan suatu gambaran bagi suatu penelitian. Jenis data dalam penelitian ini adalah data kualitatif dan kuantitatif.Data Kualitatif yang digunakan peneliti dalam penelitian ini adalah dengan melakukan wawancara mengenai gambaran umum perusahaan seperti latar belakang perusahaan yang ada didalam PD.Owabong. Sedangkan data Kuantitatif dalam penelitian ini yang digunakan sebagai data kuantitatif adalah data pengunjung PD.Owabong pada tahun 2012 - 2016. Sumber data dalam penelitian ini adalahdata Primer yang diperoleh langsung berupa hasil wawancara dan data jumlah pengunjung dari tahun 20122016. Sedangkan data sekunder dalam penelitian ini adalah data yang diperoleh dari media cetak maupun internet yang memiliki hubungan dengan penelitian ini. Populasidalam penelitian adalah para pengunjung obyek wisata Air Bojongsari yang sudah pernah mengunjungi owabong minimal dua kali ke owabong dan berusia 16 tahun - $>51$ tahun. Metode pengambilan sampel dalam penelitian ini adalah non probabilility sampling dengan teknik pengambilan sampelnya adalah dengan menggunakan teknik purposive sampling. Dalam penelitian ini terdapat 29 indikator sehingga jumlah sampelnya adalah 5 x $29=145$ sampel. Penelitian ini menggunakan Structural equation modeling (SEM), yang memberikan rekomendasikan ukuran sampel antara 100 sampai 200.Pada Penelitian ini peneliti menggunakan metode pengumpulan data yaitu kuisioner. Metode ini dilakukan dengan cara memberikan kuisioner kepada pengunjung Owabong baik dari dalam kota maupun luar kota dimana hasil kuisioner tersebut digunakan peneliti untuk melakukan penelitian.

\section{HASIL DAN PEMBAHASAN}

Model struktural pada penelitian ini dapat dilihat pada Gambar 2 dengan keseluruhan model dalah pada perhitungan Chi-Square. Hasil pengujian tersebut dapat dilihat pada output AMOS seperti pada tabel 2 . 


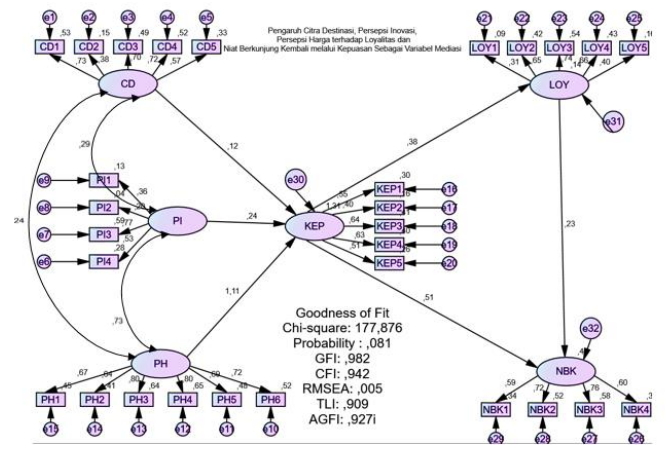

Output SEM dengan menggunakan AMOS

Tabel 2. Hasil Goodness of Fit

\begin{tabular}{lccc}
\hline Goodness of Fit Index & Cut off Value & Hasil & Keterangan \\
\hline Chi Square & Diharapkan kecil & 177,876 & Baik \\
Significant Probability & $\geq 0.05$ & 0,081 & Baik \\
CMIN/DF & $\leq 2.00$ & 1,905 & Baik \\
GFI & $\geq 0.90$ & 0,982 & Baik \\
AGFI & $\geq 0.90$ & 0,927 & Baik \\
TLI & $\geq 0.95$ & 0,909 & Marginal \\
CFI & $\geq 0.95$ & 0,952 & Baik \\
RMSEA & $\leq 0.08$ & 0,005 & Baik \\
\hline
\end{tabular}

Dari tabel 2 diatas menunjukan bahwa hasil goodness of fit telah memenuhi syarat dari cut off value yang telah ditentukan, sehingga dari hasil tersebut menunjukan bahwa model keseluruhan memenuhi kriteria sebagai goodness of fit.

\section{Analisis Hubungan Antar Konstruk}

Langkah ini digunakan untuk menguji hubungan kausalitas, maka matrik input yang dapat digunakan adalah matrik kovarians, Ferdinand (2011). Maximum Likelihood Estimation Method adalah teknik estimasi yang digunakan dalam penelitian ini. Model hipotesis dapat dilihat pada tabel 3 dibawah ini :

\section{Hasil Pengujian Dengan Maximum Likelihood}

Tabel 3. Hasil Uji Dengan Maximum Likelihood

\begin{tabular}{lllllll}
\hline & & & Estimate & S.E. & C.R. & P \\
\hline KEP & $<---$ & PH &, 656 &, 090 & 7,309 & $* * *$ \\
KEP & $<---$ & CD &, 085 &, 035 & 2,448 &, 014 \\
LOY & $<---$ & KEP &, 216 &, 083 & 2,585 &, 010 \\
\hline
\end{tabular}

Pengaruh antara citra destinasi dengan kepuasan, nilai estimate menunjukan angka sebesar 0,085 hal ini menunjukan bahwa hubungan citra destinasi dengan kepuasan bernilai positif. Nilai P bernilai 0,014 yang berarti memenuhi syarat dibawah 0,05 , sehingga H1 diterima dan dapat dinyatakan bahwa citra destinasi berpengaruh positif dan signifikan terhadap kepuasan pengunjung; 2). Pengaruh antara persepsi harga dengan kepuasan, nilai estimate menunjukan angka sebesar 0,656 hal ini menunjukan bahwa hubungan persepsi harga dengan kepuasan bernilai positif. Nilai P dilambangkan dengan tanda *** yang berarti memenuhi syarat dibawah 0,05. Karena itu H3 diterima dan dapat dinyatakan bahwa persepsi harga berpengaruh positif dan signifikan terhadap kepuasan pengunjung; 3). Pengaruh antara kepuasan dengan loyalitas, nilai estimate menunjukan angka sebesar 0,216 hal ini menunjukan bahwa hubungan 
kepuasan dengan loyalitas bernilai positif. Nilai P bernilai 0,010 yang berarti memenuhi syarat dibawah 0,05 , sehingga $\mathrm{H} 4$ diterima dan dapat dinyatakan bahwa kepuasan berpengaruh positif dan signifikan terhadap loyalitas pengunjung.

\section{Pembahasan}

Hipotesis pertama (H1) berbunyi " Citra Destinasi memiliki pengaruh positif dan signifikan terhadap kepuasan". Berdasarkan hasil pengujian hipotesis pada tabel maximum likelihooddiperoleh hasil bahwa citra destinasi berpengaruh positif dan signifikan terhadap kepuasan pengunjung dengan nilai estimate menunjukan angka sebesar 0,085 hal ini menunjukan bahwa hubungan citra destinasi dengan kepuasan bernilai positif. Nilai P bernilai 0,014 yang berarti memenuhi syarat dibawah 0,05 . Hal tersebut sesuai dengan alasan terbanyak yang diungkapkan pengunjung adalah Owabong memiliki destinasi wisata yang baik sehingga layak untuk dikunjungi.Hasil hipotesis pertama ini mendukung penelitian terdahulu yang dilakukan oleh Wang et al., 2009; Chi dan Qu, 2008; Bigne et al.,2001; Prayag dan Ryan, 2012, yang mengungkapkan bahwa citra destinasi memiliki pengaruh positif dan signifikan terhadap kepuasan pengunjung.

Hipotesis kedua (H2) berbunyi " Persepsi Harga memiliki pengaruh positif dan signifikan terhadap kepuasan". Berdasarkan hasil pengujian hipotesis pada tabel maximum likelihooddiperoleh hasil bahwa persepsi harga berpengaruh positif dan signifikan terhadap kepuasan pengunjung dengan nilai estimate menunjukan angka sebesar 0,656 hal ini menunjukan bahwa hubungan persepsi harga dengan kepuasan bernilai positif. Nilai $P$ dilambangkan dengan tanda *** yang berarti memenuhi syarat dibawah 0,05 . Pengaruh dari persepsi harga terhadap kepuasan pengunjung didukung dengan banyaknya pengunjung yang memberikan nilai positif mengenai harga yang ditawarkan oleh Owabong. Sebagian besar pengunjung merasa harga yang telah ditawarkan owabong relatif terjangkau karena harga tersebut didukung dengan banyaknya wahana yang diterima pengunjung dan berbagai macam fasilitas yang didapatkan. Hasil hipotesis kedua ini mendukung penelitian terdahulu yang dilakukan oleh Cronin et al., 2000; Anderson et al., 1994; Herman et al, 2007 yang mengungkapkan hasil penelitiannya bahwa persepsi harga memiliki pengaruh positif dan signifikan terhadap kepuasan

Hipotesis ketiga (H3) berbunyi " Kepuasan memiliki pengaruh positif dan signifikan terhadap Loyalitas". Berdasarkan hasil pengujian hipotesis pada tabel maximum likelihooddiperoleh hasil bahwa kepuasan berpengaruh positif dan signifikan terhadap loyalitas pengunjung dengan nilai estimate menunjukan angka sebesar 0,216 hal ini menunjukan bahwa hubungan kepuasan dengan loyalitas bernilai positif. Nilai $P$ bernilai 0,010 yang berarti memenuhi syarat dibawah 0,05. Berdasarkan karakteristik responden yang telah dikumpulkan, diketahui bahwa sebagian besar responden dari dalam purbalingga mengunjungi owabong lebih dari 3 kali sedangkan untuk pengunjung luar daerah purbalingga yang paling dominan adalah mengunjungi 3 kali ke owabong dalam waktu dua tahun terakhir. Hal tersebut menunjukan bahwa wisatawan merasakan kepuasan ketika mengunjungi owabong dan cenderung akan merasakan loyal untuk mendapatkan pengalaman wisata yang didukung dengan banyaknya wahana yang di tawarkan owabong.Hasil hipotesis ketiga ini mendukung penelitian terdahulu yang dilakukan oleh Bigne et al., 2001; Kozak, 2003; Chen dan Tsai, 2007; Manurung, 2009; Prayag dan Ryan, 2012 yang menyatakan bahwa kepuasan memiliki pengaruh positif dan signifikan terhadap loyalitas.

\section{KESIMPULAN DAN SARAN}

\section{Kesimpulan}

Wahana yang beragam serta keindahan alam yang di sajikan Owabong menjadi sesuatu hal yang menarik bagi pengunjung daerah maupun luar daerah. Banyaknya pengunjung yang datang ke Owabong akan mendorong kegiatan ekonomi bagi suatu daerah khususnya 
purbalingga. Owabong memiliki destinasi wisata yang baik, sehingga mampu menciptakan kepercayaan pengunjung terhadap suatu citra destinasi yang akan memberikan dampak positif bagi berkembangnya owabong. Selain itu, dengan citra destinasi positif yang dimiliki Owabong menjadikan Owabong sebagai tempat wisata yang layak untuk dikunjungi saat berlibur atau berwisata.

Harga yang ditawarkan Owabong juga sebagai penentu dalam mengembangkan owabong serta memberikan kepuasan bagi pengunjung. Hal tersebut dapat dilihat dari persepsi pengunjung terhadap harga, sebagian besar pengunjung berpendapat bahwa harga yang diterima sesuai dengan fasilitas dan manfaat yang didapatkan.

Kepuasan pengunjung yang tinggi akan menentukan loyalitas yang tinggi pula. Hal ini dapat dilihat dari frekuensi jumlah banyaknya berkunjung dari pengunjung dalam kota maupun luar kota purbalingga. Selain itu manfaat yang diperoleh pengunjung saat berlibur di owabong mampu membuat pengunjung melakukan kunjungan ulang di lain waktu. Sehingga memberikan kepuasan bagi pengunjung merupakan hal penting bagi owabong untuk meningkatkan pendapatan daerah.

Namun didalam penelitian ini ada hal yang perlu diperhatikan pihak manajemen owabong dalam menjaga loyalitas pengunjung. Sebagian besar pengunjung berpendapat bahwa owabong bukan pilihan utama dalam berwisata, hal tersebut dikarenakan aribut dan atraksi wisata yang dimiliki tempat wisata lain lebih menarik dan sesuai dengan hobby atau konsep yang ada pada diri pengujung.

\section{Saran}

Berdasarkan pembahasan, hasil penelitian dan kesimpulan yang telah dilakukan, maka terdapat saran yang dapat diberikan sebagai berikut:

Untuk Obyek Wisata Air Bojongsari (OWABONG), PD. Owabong harus menjaga kelestarian lingkungan dan alam serta mata air yang menjadi sumber utama Objek Wisata Air Bojongsari agar pengunjung memiliki keinginan untuk berkunjung kembali di masa yang akan datang dan menambahkan fasilitas-fasilitas serta wahana-wahana yang ada di Objek Wisata Air Bojongsari seperti toilet, tempat bilas, gazebo agar wisatawan berkunjung ke Owabong merasa aman dan nyaman serta memberikan pelayanan, keamanan yang terjamin bagi pengunjung.

Untuk Penelitian Selanjutnya, Bagi peneliti selanjutnya yang ingin melakukan penelitian atau melanjutkan penelitian, disarankan untuk meneruskan atau melakukan pengembangan penelitian ini dengan mencari faktor lain seperti e-wom dan lain-lain yang dapat mempengaruhi loyalitas dan niat berkunjung ulang yang dimediasi oleh kepuasan. Selain itu memperbanyak jumlah sampel penelitian agar hasilnya lebih optimal lagi.

\section{DAFTAR PUSTAKA}

Alexandris, K. Kouthouris, C dan Maligdis, A. 2006. Increasing customers' loyalty in a skiing resort The contribution of place attachment and service quality. International Journal of Contemporary Hospitality Management. Vol. 18 No. 5, pp. 414-425

Andreassen, Tor Wallin \& Lindestad, Bodil. 1998. Customer Loyalty and Complex Services: the impact of corporate image on quality, customer satisfaction and loyalty for customer with varying degrees of service expertise. International Journal of Services Industry Management, Vol. 9 No. 1, pp. 7-23.

Anuwichanont, Jirawat. (2011). The Impact of Price Perception on Customer Loyalty In The Airline Context. Journal of Bussiness and Economic Research, Vol.9.

Baker, D. A., \& Crompton, J. L. 2000. Quality, satisfaction, and behaviour intentions. Annals of Tourism Research, 27. 785-804 
Bigne, J. E., Sanchez, I., dan Andreu, L. 2009. The role of variety seeking in short and long run revisit intention in holiday destinations. International Journal of Culture, Tourism and Hospitality Research, 3(2), 103-115.

Bitner, M.J. (1990). Evaluating service encounters: the effects of physical surroundings and employee responses. Journal of Marketing. Vol. 54 No. 2, pp. 69-82.

Bosque, I. R., \& Martin, H. S. 2008. Tourist satisfaction: A cognitive-affectivemodel. Annals of Tourism Research, 35(2), 551-573

Burton S, Lichtenstein DR, Netemeyer RG, Garretson JA. (1998). A scale for measuring attitude toward private label products and examination of its psychological and behavioral correlates. J Acad Market Sci 264:293-306.

Burton, S. Lichtenstein, D.R. Netemeyer, R.G. Garretson, J.A. 1998. A scalefor measuring attitude toward private label products and examination of its psychological and behavioral correlates. Journal of the Academy of Marketing Science 26 (4), 293-306

Burton, Scot; Lichtensein, Donald R; Netemeyer, Richard G and Garretson, Judith A .(1998). A Scale for Measuring Attitude Toward Private Label Product and an Examination of Its Phsycological and Behavioral Correlates. Academy of Marketing Science Journal., 26 (4).

Chen JS, Gursoy D (2001) An investigation of tourists' destination loyalty and preferences. Int J Contemp Hospitality Manage 13(2):79-85

Chen,Ching-fu dan DungChun Tsai. 2007. How Destination Image and Evaluative Factors Affect Behavioral Intention?. Tourism Management 28, 1115-1122

Chi, C. G. Q., \& Qu, H. 2008. Examining the structural relationships of destination image, tourist satisfaction and destination loyalty: An integrated approach. Tourism management 29, 624-636.

Coban, Suzan. 2012. The effect of the citra of destination on tourist satisfaction and loyality: The case of Cappadocia. Jurnal of Social Sciences. 29, 222-232

Cronin, J. Brady, M.K dan Hult . 2000. Assessing the Effects of Quality, Value, and Customer Satisfaction on Consumer Behavioral Intentions in Service Environments. Journal of Retailing. Vol. 76, pp. 193-218.

Dick, A.S dan Basu, K. 1994. Customer Loyalty : Toward an Integrated Conceptual Framework. Journal of The Academy Marketing Science. Vol.22, p.99-113.

Ehsani, Z., Ehsani, M.H. 2014. Effect of quality and price on customer satisfaction and commitment in Iran auto industry. Journal of Marketing Vol. 63

Elvira. 2016. Pengaruh Live Performance, Kualitas Pelayanan, dan Persepsi Harga terhadap Kepuasan Penonton Sendratari Ramayana Prambanan. Tata Kelola Seni: VOL. 2 NO. 2.

Fernandha, Fransisca dan Devi. (2017). Pengaruh Pengembangan Produk Them Park dan Persepsi Harga Terhadap Kepuasan Wisatawan. Jurnal Administrasi Bisnis. Vol. 43 No.2.

Foster, B D dan John Q, Cadogan. 2000. Relationship Selling and Costumer Loyalty: An Empirical Investigation. Marketing Investigation and Planning, 18/4

Giese dan Cote. 2000. Defining Consumer Satisfaction. Academy Of Marketing Science Review Vol. 2000, No. 1.

Griffin, Jill. 2005. Customer Loyalty: Menumbuhkan dan Mempertahankan Kesetiaan Pelanggan. Jakarta : Erlangga 
Herrmann, A., Xia, L., Monroe, K.B., and Huber, F. 2007. The influence of price fairness on customer satisfaction: an empirical test in the context of automobile purchases. Journal of Product \& Brand Management, Vol. 16, pp. 49-58.

Huang, Songsan dan Cathy H.C. Hsu. 2009. Effect of Travel Motivation, Past Experience, Precevied Constraint, and Attitude on Revisit Intention. Journal of Travel Research.

Jang dan Feng. 2007. Temporal Destination Revisit Intention: The Effects of Novelty Seeking And Satisfaction. Tourism Management, 28.

Kubroa, Inayatul; Yaniadila dan Zulmi. 2017. Kontribusi Persepsi Kualitas Produk dan Harga Terhadap Kepuasan Pengunjung Cafe Di Payakumbuh. Jurnal RAP UNP, Vol. 8, No. 2.

Kozak, M. 2001. Repeaters' behavior at two distinict destinations. Annals of Tourism Research 28,784-807

Lopes, S.D.F. 2011. Destination Image: Origins, Developments and Implications". PASOS. Revista de Turismo y Ptrimonio Cultural, 9 (2), pp. 305-315

M.Mahadzirah , Manan;Abdul dan Izzati. 2011. A Structural Model Of Destination Image, Tourists' Satisfaction And Destination Loyalty. International Journal Of Business And Management Studies. Vol.3.

M.Mahadzirah dah Ghani; Nur Izaati. 2014. The Impact of Tourist Satisfaction on Destination Loyalty among European Tourists Visiting Malaysia. International Journal of Management Sciences Vol. 2, 362-371.

Maria dan Anamaria. 2013. Tourist Satisfaction With Innovation In Romanian Hotel. International Management Conference.

Mill, Robert Christie. 2000. Tourist The International Business. Open Text book for Hongkong.

Oliver, Richard L. 1980. A Cognitive Model of the Antecedents and Consequences of Satisfaction Decisions. Journal of Marketing Research, Vol. 17. No. 4, pp. 460-469.

Oliver, Richard L. 1999. Whence Consumer Loyalty. Journal of Marketing. Vol.3 , pp. 33-44.

Oppermann, M. 2000. Tourism Destination Loyalty. Journal of Traveler Research 39, 41-48.

Peter, J. P., \& Olson, J. C. (2008). Consumer behavior and marketing strategy (9th ed.). Singapore: McGraw-Hill.

Petrick, J.F., Morais, D.D., dan Norman, W.C. 2001. An examination of the determinants of entertainment vacationers' intentions to revisit. Journal of Travel Research, Vol. 40, 41- 48.

Pilelienė, Lina \& Grigaliunaite, Viktorija. 2014. Interaction between satisfaction and loyalty of Lithuanian rural tourists: a moderating effect of perceived value. Management Theory and Studies for Rural Business and Infrastructure Development.

Pizam, A., Neumann, Y. dan Reichel, A. 1978. Dimensions of tourist satisfaction with a destination. Annals of Tourism Research, 5: 314-322.

Pradini, Gigih. 2017. Pengaruh Tourism Destination Parts, Service Quality Terhadap Destination Loyalty Melalui Tourist Satisfaction Di Taman Margasatwa Ragunan. Jurnal EKSEKUTIF Volume 14.

Prayag, G. 2012. Paradise for Who? Segmenting Visitors' Satisfaction with Cognitive Image and Predicting Behavioural Loyalty, 15 (February 2011), 1-15.

Pritchard, M.P. and Howard, D.R. 1997. The loyal traveler: examining a typology of service patronag. Journal of Travelers Research. Vol. 35 No. 4, pp. 2-11.

$\mathrm{Qu}$, Hailin et al. 2011.A Model of Destination Branding: Integrating the Concepts of the Branding and Destination Image. Journal of Tourism Management. 32: 465-476. 
Richars, Greg, Julie Wilson. 2007. Tourism, Creativity, and Development. London : Routledge

Rogers, Everett M., 1983, Diffusion of Innovations, Forth Edition. New York: The Free Press.

Sethi, R., Smith, D. C., \& Park, C. W. 2001. Cross-Functional Product Development Teams, Creativity, and the Innovativeness of New Consumer Products. Journal of Marketing Research, 38(1), 73-85.

Setiawan, P.Y. (2014), The Effect of e-WOM on Destination Image, Satisfaction and Loyalty, International Journal of Business and Management Invention, Vol. 3, No. 1.

Sun, X., et al. 2013. Developing destination loyalty: The case of Hainan Island. Annals of Tourism Research, 43 : 547-577.

Tasci, Asli D. A. and Metin Kozak. 2006. Destination brands vs destination images: Do we know what we mean?. Journal of Vacation Marketing, 12 (4), p. 299-185.

Truong dan Foster. 2006. Using HOLSAT to evaluate tourist satisfaction at destination. The case of Australian holiday makers in Vietnam. Tourism Management 27, 842-855.

Wang, X., Zhang, J., gu, C.L., \& Zhen, F. 2009. Examining antecedents and consequence of tourist satisfaction: Astructural modeling approach. Tsinghua Science and technology, 14 (3), 397406.

Yoon, Y dan Uysal, M. 2005. An Examination of The Effects of Motivation and Satisfaction on Destination Loyalty: A Structural Model. Tourism Management 26. , 45-56.

Yuksel, A. 2001. Managing Customer Satisfaction and Retention: A Case of Tourist Destination Turkey. Journal of Vacation Marketing 7. 153-168.

Zebua, Manahati. 2016. Pemasaran Pariwisata: Menuju Festival Sail Daerah. Yogyakarta: Deepublish. 